\title{
From Type-1 Diabetes HPA Axis to the Disease Complications
}

\author{
Rafael C Torres, Jessika P Prevatto, Patricia MR Silva, Marco A Martinsand and Vinicius F Carvalho*
}

Laboratório de Inflamação, Instituto Oswaldo Cruz, Fundação Oswaldo Cruz; Av. Brasil, Brazil

\begin{abstract}
Diabetes is a chronic metabolic disease whose incidence is increasing over the years in both developed and developing countries. Uncontrolled or poor controlled diabetic patients present several secondary complications induced by hyperglycemia, which are involved with the high morbidity and mortality of this disease. Moreover, the reduction of insulin production in diabetic patients induces increase of the activity of HPA axis that results in an increase of glucocorticoid production. This review gives an update of the state-of-the-art concerning the relationship of hyperactivity of HPA axis observed in type 1diabetic patients and the development of the disease complications.
\end{abstract}

Keywords: Diabetes; Glucocorticoid; Glucose metabolism; Hormones; HPA axis; Insulin

\section{Introduction}

Diabetes mellitus is a chronic metabolic disease of multiple etiologies characterized by deficiency in insulin secretion, action or both, which result in hyperglycemia. This hyperglycemia induces a number of secondary complications including polyuria, glycosuria, polydipsia and polyphagia that are the first clinical signs of diabetes [1]. Patients may present several forms of diabetes including type 1 and type 2. Type 1 diabetes results from autoimmune destruction of pancreatic B-cells, which leads to a drastic or absolute deficiency in the insulin levels [2,3], while type 2 diabetes is characterized by deficiency in insulin action, caused by genetic factors associated with unsound habits, being obesity an important risk factor to the disease development $[4,5]$.

Diabetes is considered a huge public health problem. Its incidence is increasing over the years in countries at all stages of economic and social development, and its chronic nature and complications make it a very expensive disease. According to the International Diabetes Federation, more than 371 million people have diabetes and only in 2012, 4.8 million people died due to diabetes and more than 471 billion of United State dollars (USD) were spent on diabetic's healthcare. Beyond the direct costs, there are indirect costs of the illness. Many diabetic patients are unable to continue working due to chronic complications or remain with some limitation in their professional performance [6]. Although type 1 diabetes, once called juvenile diabetes, begins mainly in children and adolescents, there are rising rates of adults developing the disease [7]. Unfortunately, maybe as consequence of deficient medical care, many adults with autoimmune diabetes have been diagnosed withtype 2 diabetes, which make more difficult the correct treatment and may exposes the patients to the disease complications [8], including cardiovascular disease, retinopathy, nephropathy and neuropathy [9-12]. It is notorious the participation of hyperglycemia in the diabetes complications, nevertheless other diabetic features may contribute to these dysfunctions, directly leading to themor even exacerbating the hyperglycemia. One important factor to be considerate is the hyperactivity of the hypothalamic-pituitary-adrenal (HPA) axis in diabetics [13].

\section{HPA Axis}

The HPA axis is an integral part of a neuroendocrine system with an important role in maintaining homeostasis through adaptive change under physical and psychological demands. This axis regulates the glucocorticoid hormones production and release. In basal conditions, the activity of HPA axis is regulated by a circadian rhythm driven by centrally-coordinated mechanism integrated in the hypothalamic suprachiasmatic nucleus and strongly associated with the day/night cycles [14]. This mechanism named CLOCK system is a high conserved, ubiquitous molecular "clock" that synchronizes their daily rhythms in endocrine system to solar time by direct retinal afferents [15,16]. In humans, that are diurnal animals, the light activates central master CLOCK in the hypothalamus which influences the HPA axis and promotes a high production of glucocorticoids in the early morning and a decrease of glucocorticoid levels in the late evening [14]. Furthermore, recent evidence suggests a contribution of peripheral "clocks" on the control of the glucocorticoids production, as adrenal gland-intrinsic rhythm. In particular, the steroidogenic acute regulatory protein (StAR) seems to be an important link between the CLOCK system and the glucocorticoids synthesis in adrenals [17]. Studies show that adrenal StAR levels present daily variations even after 2 days of constant dark conditions [18].

The HPA axis activation needs a complex and dynamic interplay between the sympathetic nervous system, neurons in the paraventricular (PVN) nucleus of the hypothalamus, anterior pituitary and peptidic mediators resulting in the release of glucocorticoids to circulation. Hypothalamic secretion of corticotropin releasing factor (CRF) and vasopressin (AVP) stimulates pituitary adrenocorticotrophic cells to produce adrenocorticotrophic hormone $(\mathrm{ACTH})$, which in turn activates the glucocorticoids production in adrenal cortex. CRF is a 41 amino acid-peptide hormone produced by hypothalamic PVN and the major stimulator of pituitary ACTH production at normal conditions [19]. It acts via CRF receptor type 1 (CRF1), a seven-transmembranedomain G protein-coupled receptor (GPCR) expressed not only in the anterior pituitary but also in the brain with major expression on cerebral cortex, amygdala and hippocampus [20]. Via the pituitary portal system, CRF activates the ACTH production in a mechanism

*Corresponding author: Vinicius F Carvalho, Laboratório de Inflamação, Fundação Oswaldo Cruz, Av. Brasil, $n^{\circ} 4365$, Manguinhos, Rio de Janeiro, Brazil, Tel: 55-21-2562-1334; Fax: 55-21-2562-1357; E-mail: vfrias@ioc.fiocruz.br

Received March 27, 2013; Accepted April 22, 2013; Published April 26, 2013

Citation: Torres RC, Prevatto JP, Silva PMR, Martinsand MA, Carvalho VF (2013) From Type-1 Diabetes HPA Axis to the Disease Complications. J Diabetes Metab S12: 002. doi:10.4172/2155-6156.S12-002

Copyright: @ 2013 Torres RC, et al. This is an open-access article distributed under the terms of the Creative Commons Attribution License, which permits unrestricted use, distribution, and reproduction in any medium, provided the original author and source are credited. 
potentiated by AVP, a cyclic nonapeptide also produced in PVN with a wide range of functions including fluid metabolism and regulation of pituitary corticotroph cells. AVP acts through GPCR vasopressin $1 \mathrm{~b}$ receptors (AVP1b) to enhance ACTH production in anterior pituitary [21].

ACTHisobtainedafterthecleavageofpituitaryproopiomelanocortin (POMC) by specific pro-hormone convertases [22]. Once synthesized, the hormone is secreted into the blood circulation reaching the adrenal glands, where it binds to melacortin-2-receptors (MC2R) in fasciculate zone of the gland cortex. The binding of ACTH to MC2R results in stimulation of adenylyl cyclase with subsequent activation of protein kinase $\mathrm{A}$, which leads to gene transcription involved in glucocorticoids production [23]. Thus, glucocorticoids are synthesized from cholesterol by a series of biochemical steps catalyzed by cytochrome $\mathrm{P} 450$ enzymes that involve terminal reactions of hydroxylation leading to the production of two active forms of this hormone by adrenocortical steroidogenic cells, cortisol and corticosterone [24]. Cortisol, also called hydrocortisone, is the most important human glucocorticoid, while corticosterone is the major glucocorticoid present in rodents. Although this difference in the profile of circulating glucocorticoids, both hormones present the same effects in the organism, including regulating metabolic activity, immune function and behavior [25-27].

Besides being regulated by circadian rhythm, the HPA axis is also the major system which responds to adaptive stress, part of a complex homeostatic control that acts to provide resistance to changes in the internal environment [21]. The characteristics of stress response are strongly associated with the stressor agents themselves, intensity, duration and individual psychological resources which determine the resulting coping strategies [28]. When subjected to a stressor, appropriate brain regions, depending on particular characteristics of the stressors, leads to a HPA response that begins on the amygdala, a key component of the limbic system that coordinates negative emotional responses to threatening stimulus [29]. Once activated, amygdala conveys their message to the hypothalamus, leading to the HPA axis activation and glucocorticoids production. Besides its immunological functions, glucocorticoids affect energetic metabolism and cardiovascular responsiveness preparing tissues to physical "needs" that may be pivotal to the body response to stress [21]. However, situations in which there is a prolonged exposure to stressors or failure of the HPA axis control and high productions of cortisol, glucocorticoids can bind to its receptor in hippocampus, modifying brain functions [30]. This is supposed to be a key mechanism to control the potentially harmful hyperactivation of HPA axis.

Both basal and stress related HPA axis activity are regulated by a glucocorticoid negative feedback which occurs on slow and fast time frames [31]. The slow feedback mechanism is mediated by genomic glucocorticoid signaling via glucocorticoid (GR) and mineralocorticoid receptors (MR) [32]. Glucocorticoid acts on the hypothalamus PVN and pituitary gland repressing the production of CRF and $\mathrm{ACTH}$, respectively, which contributes to the restoration of the axis homeostasis [33]. Fast feedback inhibition of the HPA axis is associated with nongenomic pathways and occurs within minutes. Some authors suggest a participation of membrane-associated GR and MRon this phenomenon instead of the classic intracellular via of activations of these receptors [31,34]. Moreover, recent data suggest a role of the enzyme 11beta hydroxysteroid dehydrogenase type 1 (11ßHSD1) in HPA axis feedback. This enzyme modulates glucocorticoid signaling in various tissues converting inactive cortisone in its active form, and is expressed in human hypothalamus colocalised with CRF and AVP. 11ßHSD1 may amplify the negative feedback of the axis through autocrine conversion of cortisone to cortisol [35].

Thus, the comprehension of HPA axis operation, including production and regulation of glucocorticoids hormones, is crucial to understanding the possible mechanisms associated with the development and/or aggravation of stress-related diseases. In general, these stressors are psychological, culminating in fight-or-flight responses, however the hyperactivity of HPA axis can be associated with non-psychological stressors, as metabolic disruption observed in diabetes.

\section{HPA Axis in Diabetes}

Diabetic patients present several similar complications seen in patients with Cushing's syndrome, including hypertension, immune response suppression, muscle weakness and increased risk of depression, leading to the suggestion that diabetics may present abnormality in the HPA axis [36]. In fact, patients with Diabetes mellitus present increased activity of the HPA axis, resulting in elevated circulating levels of glucocorticoids along with increased urinary free cortisol levels [37]. We and others showed that type 1 diabetic animals also present high levels of serum glucocorticoids [13,38]. One explanation for the hyperactivity of HPA axis in diabetics is the effect of hyperglycemia-induced stress, once high glucose levels induce increase of glucocorticoid production as demonstrated by systems such as zebra fish embryos and primary rat adrenocortical cells in vitro $[39,40]$. The effect of hyperglycemia on HPA axis may be related to the activation of polyol pathway, an alternative route of glucose metabolism, once adrenal glands present high levels of aldose reductase, major enzyme of polyol pathway, and this enzyme is reported as responsible for generating intermediates in the catabolism of corticosteroid hormones in these glands [41,42]. Moreover, we previously showed that the inhibition of aldose reductase was able to restore the hypercorticolism observed in alloxan-diabetic rats [43].

In animal models of type 1 diabetes, the hyperactivity of HPA axis is associated with an increase in central drive and an impaired in glucocorticoid negative feedback sensitivity [13]. These animals present dynamic changes in hypothalamus, pituitary and adrenal glands, which results in high levels of AVP and increase in POMC expression by hypothalamus with consequent increment in ACTH production [4446]. Furthermore, we showed that alloxan-diabetic animals present a high expression of ACTH receptors (MC2R) in fasciculate zone of adrenal glands (Figure 1). The decreased of glucocorticoid negative feedback sensitivity of HPA axis in type 1 diabetic animals was observed by us and other after dexamethasone suppression test $[13,38]$ This inability of glucocorticoids in doing the negative feedback of HPA axis in alloxan-diabetic animals can be explained by the fact that these animals present a down-regulation of GR and MR in pituitary (Figure 1). The hyperactivity of HPA axis in type 1 diabetes is associated with decrease in insulin levels, once insulin treatment normalize HPA axis activity by suppression of ACTH and glucocorticoid secretion in a mechanism possibly associated with an increase in GR mRNA levels in pituitary, and presumably an improvement on glucocorticoid feedback at the corticotroph cells $[13,47]$.

Besides the reduction of insulin levels in diabetic animals appear to have a direct role in hyperactivity of HPA axis, since its administration restores the glucocorticoid production, the insulin deficiency can also act indirectly through alterations in homeostasis of other hormones, including increasing of glucagon and decreasing of leptin and prolactin 
Citation: Torres RC, Prevatto JP, Silva PMR, Martinsand MA, Carvalho VF (2013) From Type-1 Diabetes HPA Axis to the Disease Complications. J Diabetes Metab S12: 002. doi:10.4172/2155-6156.S12-002

Page 3 of 8
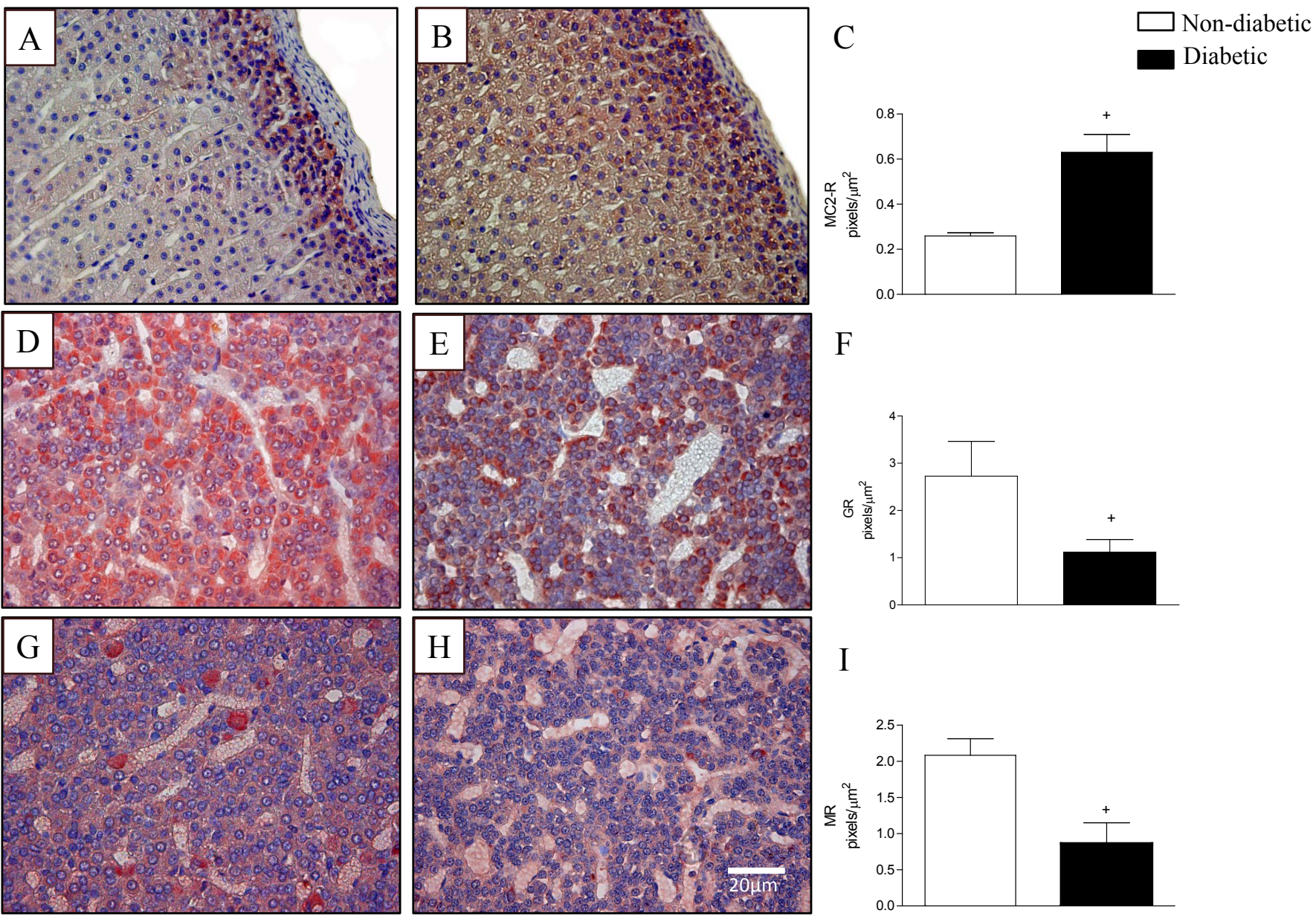

F
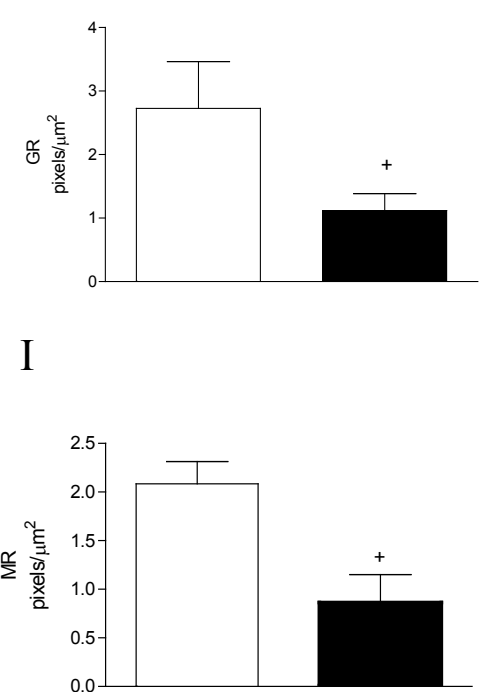

Figure 1: Diabetic rats present increased levels of MC2R in adrenal glands and reduced expression of corticosteroid receptors in pituitary.

Type 1 diabetes was induced by a single i.v. injection of alloxan $(40 \mathrm{mg} / \mathrm{kg})$ and analyses were performed after 21 days. The receptors expression was evaluated by immunohistochemistry. We observed an increase in MC2R expression in the adrenals of diabetic (B) compared with non-diabetic animals (A). Besides, both the expression of GR and MR were found down-regulated under diabetic conditions ( $E$ and $H$, respectively) in anterior pituitary compared with control animals ( $D$ and $G$, respectively).Quantitative evaluations of MC2R, GR and MR labeling are seen in panels $C, F$ and I, respectively.Positive reactions are determined by the red color. Data are expressed as mean \pm S.E.M. of at least 3 animals, ${ }^{+} p<0.05$ as compared to non-diabetic animals.

levels [47-49]. Glucagon stimulates HPA axis by a hypothalamic mechanism and the subsequent cortisol synthesis in human beings. Moreover, an intracerebroventricular (icv) administration of glucagon is able to increase corticosterone levels in chickens, suggesting that glucagon can activate the HPA axis [50]. Thereby, the existence of increased levels of glucagon in diabetic patients may contribute to the overproduction of the glucocorticoids in these subjects.

Leptin can modulate de HPA axis response to stress in rodents and humans by a peripherally and centrally mechanism. Leptin acts in all levels of the axis: hypothalamus, pituitary and adrenal glands inhibiting the glucocorticoids production [51]. Besides, the chronic subcutaneous leptin infusion in rhesus monkeys reduces the HPA axis responsiveness enhancing the glucocorticoid negative feedback and reducing CRFinduced increase in both ACTH and cortisol [52]. Prolactin also inhibits the reactivity of HPA axis, once in hyperprolactinemia condition animals present a reduced response to different stressor agents [53,54]. In addition, during acute Trypanossomacruzi infection the HPA axis hyperactivity and the increase of glucocorticoids production were shown inversely correlated with the prolactin levels [55]

It is noteworthy that glucagon signaling is able to induce the increase of cAMP levels and the activation of protein kinase A (PKA) that are fundamental to a number of the hormone functions $[56,57]$. On the other hand, is described that insulin, leptin and prolactin proteins act by the intracellular phosphoinositide 3-kinase (PI3K) pathway determining different biological functions [58-61]. Interesting, substances that elevate cAMP levels like inhibitors of phosphodiesterase 4 (PDE 4) also increase basal HPA axis activity, increasing plasma concentrations of ACTH and corticosterone [62,63]. Oppositely, PI3K pathway is associated with HPA axis inhibition. Some antipsychotic drugs can down-regulate the human CRF gene promoter function by activating PI3K/Akt dependent pathway, indicating a possible molecular mechanism associated with HPA axis control [64]. Thereby, the intracellular increase of cAMP levels and reduction of PI3K activation in diabetes associated with increase in glucagon levels and decrease of insulin, prolactin and leptin, respectively, may be correlated with the hyperactivity of the HPA axis in diabetic patients.

In addition to diabetes inducing hyperactivity of HPA axis, the opposite may also happen. Non-diabetic patients can present functional and non-functional adrenocortical tumors or nodules, called incidentalomas. Functional masses can induce hyperactivity of 
HPA axis and subclinical Cushing disease characterized by an increase on glucocorticoid levels [65]. The hypercorticolism observed in these Cushing patients can leadto hypertension, obesity and insulin resistance which in turn may be associated with a late-onset diabetes [36]. Besides, patients with non-functioning adrenocortical tumors also present high prevalence of glucose tolerance, insulin resistance and hypertension, but independently of hyperactivity of HPA axis [66].

\section{The Role of Hyperactivity of HPA Axis on Diabetic Complications Development}

Diabetes is a disease associated with a wide spectrum of complications secondary to hyperglycemia that have direct impact in the life of patients, frequently generating deep limitation on professional and personal abilities or even causing death. The main pathological diabetes manifestations are originated by vascular and/or neuronal dysfunction compromising the correctly function of different physiological systems and affecting several organs, including kidneys, blood vessels and heart [67]. Beyond hyperglycemia, hyperactivity of HPA axis with consequent increased levels of glucocorticoids in diabetic patient's bloodstream is a challenge for the control of several diabetic complications, as impaired wound healing, increased infection/sepsis risk, atherosclerosis, hypertension and neurological disturbs that may prejudice cognitive abilities [68-70].

Wound healing is a complex event that involves several fundamental steps, including inflammation, re-epithelialization, angiogenesis and granular tissue formation [68]. In diabetes, all stages of wound healing are compromised [71], in association with reactive oxygen species (ROS) formation, down-regulation of inflammatory response, inhibition of angiogenesis and extracellular matrix deposition [72]. The hyperactivity of HPA axis in diabetes seems to have an important role in impairment of wound healing, once dexamethasone impaired collagen synthesis by fibroblasts and reduced proliferation, migration and contraction of these cells both in non-diabetic and diabetic animals [73]. Moreover, these animals over stress conditions present increased glucocorticoids levels which compromise the immune system and inflammatory response [74-78]. Furthermore, glucocorticoids can increase ROS production $[79,80]$ and inhibit angiogenesis by reducing VEGF expression [81,82]. All these glucocorticoids effects are associated with impaired wound healing observed in diabetes.

Beyond impaired wound healing, the immunosuppress and antiinflammatory effects of glucocorticoids are important to development of others diabetic complications, including less incidence of allergic diseases and a high risk of opportunists infection $[69,83]$. We showed that diabetic animals present a less protein leakage and accumulation of eosinophils in skin and pleural cavity after antigen challenge and a reduction in intestine hemorrhage and mortality after anaphylactic shock with a relationship with a decrease in mast cell numbers and reactivity [84-86].

The high incidence of opportunist infection in diabetic patients, including tuberculosis, pneumonia and sepsis, is associated with abnormalities in neutrophil chemotaxis, adhesion and intracellular killing together with defects in antibody responses and complement opsonisation [87]. These alterations in phagocytes and lymphocytes functions and consequent predisposition to infection diseases in diabetics are relationship with hyperglycemia and insulinopenia [88]. However, the high circulating glucocorticoids levels in diabetics could also contribute to the elevated infection incidence in these patients, once glucocorticoid therapy is associated with increased risk of opportunistic infection development, including tuberculosis and pneumonia [89-91].

Diabetic patients also present high incidence of hypertension which accelerates the decrease in renal function, retinopathy and cerebral disorders [92]. Hyperactivity of HPA axis observed in Cushing disease or even pharmacological administration of glucocorticoids favors the hypertensive state [93]. Besides, the glucocorticoid promiscuous activation of MR resulting in renal sodium retention, volume expansion and increase in blood pressure. This steroid hormone can also up-regulate angiotensin II type 1 receptors on smooth muscle cell and reduce neuronal nitric oxide release in animal arteries $[94,95]$. Hypertension is a risk factor to atherosclerosis, another risk factor associated with elevated morbidity and mortality in patients with diabetes [96]. In addition to the glucocorticoids participation on hypertension, the HPA axis activation also directly contributes to atherosclerosis development, since interactions of glucocorticoids with the cells of the heart and vascular wall may alter their structure, function and facilitate plaque development independent of alterations on plasmatic cholesterol [97-99].

Finally, diabetes is also a risk factor for stroke, cognitive impairment and nerve damage [100,101]. Neurological complications in diabetic patients are often associated with hyperglycemia, which induces polyol pathway activation, enhances oxidative stress and formation of advanced glycation end products (AGEs) that are important predictive features to nerve tissue injury $[102,103]$. Impaired insulin or C-peptide actions together with dyslipidemia are also involved in diabetic neuropathies development $[104,105]$. In this context, the HPA axis hyperactivity could be an important player in neurological alterations observed in diabetic patients, once an increase in glucocorticoids levels is associated with impaired hippocampus-depended memory, synaptic plasticity and neurogenesis in diabetic animals [106].

Moreover, other diseases associated with neurodegenerative illness, including Alzheimer and Cushing's syndrome, present hyperactivity of HPA axis and elevated cortisol levels [107,108]. In an Alzheimer mice model, treatment of animals with PPAR-gamma agonist attenuates the mice learning and memory deficits in close relationship with reduction of serum glucocorticoid levels [109]. Furthermore, we reported that treatment of alloxan-diabetic rats with rosiglitazone induced a reduction in corticosterone levels by activation of PPAR-gamma [110] In addition, the HPA axis hyperactivity, by causing hypercorticolism and increased CRF receptor genes expression may explain the association between diabetes and depression [111,112], since both $\mathrm{CRF}$ and cortisol stimulate catecholamines release which is implicated in anxiety disturbs [113,114]. In fact, the diabetic complications associated with hypercorticolism are related with GR activation, once pharmacological blockage using GR antagonist ameliorate the wound healing, restore the mast cell numbers and the reactivity to local and systemic antigenic challenge, reduce arterial pressure response to stress, and attenuate stroke, cognitive impairment and nerve damage in diabetes or other hypercorticolism associated illness [115-120].

\section{Conclusion}

The focus of this review is on the mechanisms involved with the hyperactivity of HPA axis and its relationship with the complications observed in type-1diabetic subjects. As illustrated in figure 2, we suggested that hyperactivity of HPA axis in diabetics is associated with high levels of circulating ACTH and glucocorticoids, and ACTH receptor in adrenal glands, beyond an impaired in glucocorticoid negative feedback due to a reduction in the expression of GR and 
Citation: Torres RC, Prevatto JP, Silva PMR, Martinsand MA, Carvalho VF (2013) From Type-1 Diabetes HPA Axis to the Disease Complications. J Diabetes Metab S12: 002. doi:10.4172/2155-6156.S12-002

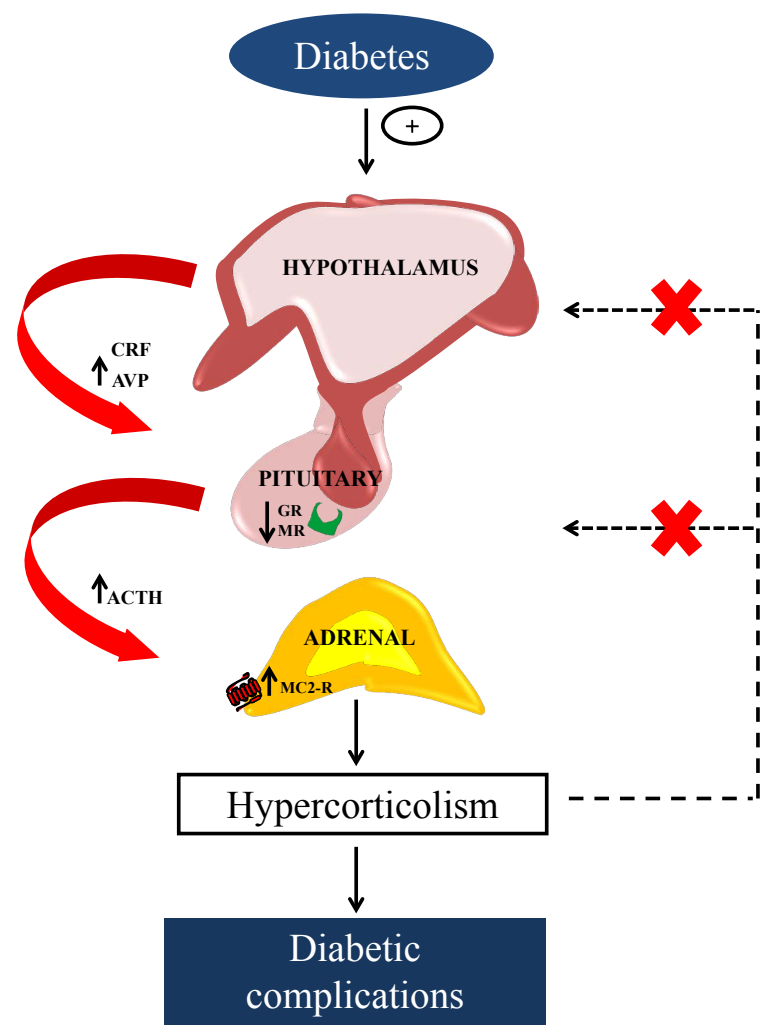

Figure 2: Schematic representation of physiological and molecular mechanisms responsible for hyperactivity of HPA axis observed in type 1 diabetes.

Diabetes induces increase in AVP, ACTH and MC2R levels and decrease of glucocorticoid negative feedback. The impaired of negative feedback in diabetics is related with reduction of GR and MR expression in pituitary. Together, these alterations in HPA axis lead to increase of glucocorticoid levels culminating in the development and/or aggravation of diabetic complications.

MR in pituitary. Moreover, this increase in glucocorticoid levels is in close-relationship with diabetic complications development and/or aggravation.

\section{Acknowledgments}

This study was supported by Fundação deAmparo à Pesquisa do Estado do Rio de Janeiro (FAPERJ), Conselho Nacional de Desenvolvimento Cientifico e Tecnologico (CNPq), and PAPES VI-FIOCRUZ,Brazil.

\section{References}

1. van Belle TL, Coppieters KT, von Herrath MG (2011) Type 1 diabetes: etiology, immunology, and therapeutic strategies. Physiol Rev 91: 79-118.

2. Chen $W$, Xie A, Chan $L$ (2013) Mechanistic basis of immunotherapies for type 1 diabetes mellitus. Transl Res 161: 217-229.

3. Di Gialleonardo V, de Vries EF, Di Girolamo M, Quintero AM, Dierckx RA, et al. (2012) Imaging of $\hat{i}^{2}$-cell mass and insulitis in insulin-dependent (Type 1) diabetes mellitus. Endocr Rev 33: 892-919.

4. Wilson V (2012) Cognitive impairment in patients with diabetes. Nurs Stand 27: 44-49.

5. Lu J, Xie G, Jia W, Jia W (2013) Metabolomics in human type 2 diabetes research. Front Med 7: 4-13.

6. International Diabetes Federation IDF (2011) Diabetes Atlas ( $5^{\text {th }}$ edn) Brussels, Belgium: International Diabetes Federation.

7. Guglielmi C, Palermo A, Pozzilli $P$ (2012) Latent autoimmune diabetes in the adults (LADA) in Asia: from pathogenesis and epidemiology to therapy. Diabetes Metab Res Rev 28 Suppl 2: 40-46.
8. Cho YM, Kim JT, Ko KS, Koo BK, Yang SW, et al. (2007) Fulminant type diabetes in Korea: high prevalence among patients with adult-onset type 1 diabetes. Diabetologia 50: 2276-2279.

9. Imam K (2012) Clinical features, diagnostic criteria and pathogenesis of diabetes mellitus. Adv Exp Med Biol 771: 340-355

10. Heltianu C, Guja C (2011) Role of Nitric Oxide Synthase Family in Diabetic Neuropathy. J Diabetes Metab S5: 002.

11. Kytö JP, Lindström-Karjalainen M, Summanen PA (2012) Not Only Diabetic Retinopathy - Retinal Vascular Lesions and Signs in Diabetic Patients: Description and Associations. J Diabetes Metab S3: 003.

12. Mongkolsomlit S, Rawdaree P, Komoltri C, Tawichasri C, Patumanond aJ (2012) Effect of Angiotensin-Converting Enzyme Inhibitors and/or Angiotensin Receptor Blockers on the Prevention of Death in Patients with Type 2 Diabetes and Undetermined Nephropathy : Five-Year Survival Data. J Diabetes Metab 3: 188.

13. Chan O, Inouye K, Vranic M, Matthews SG (2002) Hyperactivation of the hypothalamo-pituitary-adrenocortical axis in streptozotocin-diabetes is associated with reduced stress responsiveness and decreased pituitary and adrenal sensitivity. Endocrinology 143: 1761-1768.

14. Nader N, Chrousos GP, Kino T (2010) Interactions of the circadian CLOCK system and the HPA axis. Trends Endocrinol Metab 21: 277-286.

15. Charmandari E, Chrousos GP, Lambrou GI, Pavlaki A, Koide H, et al. (2011) Peripheral CLOCK regulates target-tissue glucocorticoid receptor transcriptional activity in a circadian fashion in man. PLoS One 6: e25612.

16. Hastings M, O'Neill JS, Maywood ES (2007) Circadian clocks: regulators of endocrine and metabolic rhythms. J Endocrinol 195: 187-198.

17. Son GH, Chung S, Kim K (2011) The adrenal peripheral clock: glucocorticoid and the circadian timing system. Front Neuroendocrinol 32: 451-465.

18. Son GH, Chung S, Choe HK, Kim HD, Baik SM, et al. (2008) Adrenal periphera clock controls the autonomous circadian rhythm of glucocorticoid by causing rhythmic steroid production. Proc Natl Acad Sci U S A 105: 20970-20975.

19. Braquehais MD, Picouto MD, Casas M, Sher L (2012) Hypothalamic-pituitaryadrenal axis dysfunction as a neurobiological correlate of emotion dysregulation in adolescent suicide. World J Pediatr 8: 197-206.

20. Kageyama K, Suda T (2009) Role and action in the pituitary corticotroph of corticotropin-releasing factor (CRF) in the hypothalamus. Peptides 30: 810816

21. Roper J, O'Carroll AM, Young W 3rd, Lolait S (2011) The vasopressin Avpr1b receptor: molecular and pharmacological studies. Stress 14: 98-115.

22. Wardlaw SL (2011) Hypothalamic proopiomelanocortin processing and the regulation of energy balance. Eur J Pharmacol 660: 213-219.

23. Gorrigan RJ, Guasti L, King P, Clark AJ, Chan LF (2011) Localisation of the melanocortin-2-receptor and its accessory proteins in the developing and adult adrenal gland. J Mol Endocrinol 46: 227-232.

24. Davies E, MacKenzie SM (2003) Extra-adrenal production of corticosteroids Clin Exp Pharmacol Physiol 30: 437-445.

25. Barnes PJ (2011) Glucocorticosteroids: current and future directions. $\mathrm{Br}$ Pharmacol 163: 29-43.

26. Rose AJ, Vegiopoulos A, Herzig S (2010) Role of glucocorticoids and the glucocorticoid receptor in metabolism: insights from genetic manipulations. Steroid Biochem Mol Biol 122: 10-20.

27. Herman JP, McKlveen JM, Solomon MB, Carvalho-Netto E, Myers B (2012) Neural regulation of the stress response: glucocorticoid feedback mechanisms. Braz J Med Biol Res 45: 292-298.

28. Faravelli C, Lo Sauro C, Lelli L, Pietrini F, Lazzeretti L, et al. (2012) The role of life events and HPA axis in anxiety disorders: a review. Curr Pharm Des 18 5663-5674.

29. Feng B, Liu JC, Zhang J, Ozaki KI, Guo YY, et al. (2013) Anxiolytic Actions of Motilin in the Basolateral Amygdala. Mol Neurobiol .

30. Graeff FG, Garcia-Leal C, Del-Ben CM, Guimarães FS (2005) Does the panic attack activate the hypothalamic-pituitary-adrenal axis? An Acad Bras Cienc 77: 477-491.

31. Evanson NK, Tasker JG, Hill MN, Hillard CJ, Herman JP (2010) Fast feedback 
Citation: Torres RC, Prevatto JP, Silva PMR, Martinsand MA, Carvalho VF (2013) From Type-1 Diabetes HPA Axis to the Disease Complications. J Diabetes Metab S12: 002. doi:10.4172/2155-6156.S12-002

inhibition of the HPA axis by glucocorticoids is mediated by endocannabinoid signaling. Endocrinology 151: 4811-4819.

32. Ginsberg AB, Campeau S, Day HE, Spencer RL (2003) Acute glucocorticoid pretreatment suppresses stress-induced hypothalamic-pituitary-adrenal axis hormone secretion and expression of corticotropin-releasing hormone hnRNA but does not affect c-fos mRNA or fos protein expression in the paraventricular nucleus of the hypothalamus. J Neuroendocrinol 15: 1075-1083.

33. Heitzer MD, Wolf IM, Sanchez ER, Witchel SF, DeFranco DB (2007) Glucocorticoid receptor physiology. Rev Endocr Metab Disord 8: 321-330.

34. Atkinson HC, Wood SA, Castrique ES, Kershaw YM, Wiles CC, et al. (2008) Corticosteroids mediate fast feedback of the rat hypothalamic-pituitary-adrenal axis via the mineralocorticoid receptor. Am J Physiol Endocrinol Metab 294 E1011-1022.

35. Bisschop PH, Dekker MJ, Osterthun W, Kwakkel J, Anink JJ, et al. (2013) Expression of $11 \hat{i}^{2}$-hydroxysteroid dehydrogenase type 1 in the human hypothalamus. J Neuroendocrinol 25: 425-432.

36. Andrews RC, Herlihy O, Livingstone DE, Andrew R, Walker BR (2002) Abnormal cortisol metabolism and tissue sensitivity to cortisol in patients with glucose intolerance. J Clin Endocrinol Metab 87: 5587-5593.

37. Roy MS, Roy A, Brown S (1998) Increased urinary-free cortisol outputs in diabetic patients. J Diabetes Complications 12: 24-27.

38. e Silva PM, Carvalho VF, Cordeiro RS, Martins MA (2009) Down-regulation of allergic responses in conditions of experimental diabetes: a role for glucocorticoids? Neuroimmunomodulation 16: 13-18.

39. Astort F, Repetto EM, Martínez Calejman C, Cipelli JM, Sánchez R, et al. (2009) High glucose-induced changes in steroid production in adrenal cells. Diabetes Metab Res Rev 25: 477-486.

40. Powers JW, Mazilu JK, Lin S, McCabe ER (2010) The effects of hyperglycemia on adrenal cortex function and steroidogenesis in the zebrafish. Mol Genet Metab 101: 421-422

41. Wermuth B, Monder C (1983) Aldose and aldehyde reductase exhibit isocorticosteroid reductase activity. Eur J Biochem 131: 423-426.

42. Matsuura K, Deyashiki Y, Bunai Y, Ohya I, Hara A (1996) Aldose reductase is a major reductase for isocaproaldehyde, a product of side-chain cleavage of cholesterol, in human and animal adrenal glands. Arch Biochem Biophys 328: 265-271.

43. Carvalho VF, Barreto EO, Serra MF, Cordeiro RS, Martins MA, et al. (2006) Aldose reductase inhibitor zopolrestat restores allergic hyporesponsiveness in alloxan-diabetic rats. Eur J Pharmacol 549: 173-178.

44. Dheen ST, Tay SS, Wong WC (1994) Arginine vasopressin- and oxytocin-like immunoreactive neurons in the hypothalamic paraventricular and supraoptic nuclei of streptozotocin-induced diabetic rats. Arch Histol Cytol 57: 461-472.

45. Saravia FE, Gonzalez SL, Roig P, Alves V, Homo-Delarche F, et al. (2001) Diabetes increases the expression of hypothalamic neuropeptides in a spontaneous model of type I diabetes, the nonobese diabetic (NOD) mouse. Cell Mol Neurobiol 21: 15-27.

46. Zelena D, Mergl Z, Makara GB (2006) The role of vasopressin in diabetes mellitus-induced hypothalamo-pituitary-adrenal axis activation: studies in Brattleboro rats. Brain Res Bull 69: 48-56.

47. Chan O, Chan S, Inouye K, Vranic M, Matthews SG (2001) Molecular regulation of the hypothalamo-pituitary-adrenal axis in streptozotocin-induced diabetes: effects of insulin treatment. Endocrinology 142: 4872-4879.

48. Wang J, Obici S, Morgan K, Barzilai N, Feng Z, et al. (2001) Overfeeding rapidly induces leptin and insulin resistance. Diabetes 50: 2786-2791.

49. Wang T, Lu J, Xu Y, Li M, Sun J, et al. (2013) Circulating Prolactin Associates With Diabetes and Impaired Glucose Regulation: A population-based study. Diabetes Care .

50. Honda K, Kamisoyama H, Uemura T, Yanagi T, Saito N, et al. (2012) The mechanism underlying the central glucagon-induced hyperglycemia and anorexia in chicks. Comp Biochem Physiol A Mol Integr Physiol 163: 260-264.

51. Roubos EW, Dahmen M, Kozicz T, Xu L (2012) Leptin and the hypothalamopituitary-adrenal stress axis. Gen Comp Endocrinol 177: 28-36.

52. Wilson ME, Fisher J, Brown J (2005) Chronic subcutaneous leptin infusion diminishes the responsiveness of the hypothalamic-pituitary-adrenal (HPA) axis in female rhesus monkeys. Physiol Behav 84: 449-458.
53. Seggie JA, Brown GM (1975) Stress response patterns of plasma corticosterone, prolactin, and growth hormone in the rat, following handling or exposure to novel environment. Can J Physiol Pharmacol 53: 629-637.

54. Schlein PA, Zarrow MX, Denenberg VH (1974) The role of prolactin in the depressed or 'buffered' adrenocorticosteroid response of the rat. J Endocrino 62: 93-99.

55. Lepletier A, de Frias Carvalho V, Morrot A, Savino W (2012) Thymic atrophy in acute experimental Chagas disease is associated with an imbalance of stress hormones. Ann N Y Acad Sci 1262: 45-50.

56. Gagnon J, Anini Y (2013) Glucagon stimulates ghrelin secretion through the activation of MAPK and EPAC and potentiates the effect of norepinephrine. Endocrinology 154: 666-674.

57. Jiang G, Zhang BB (2003) Glucagon and regulation of glucose metabolism. Am J Physiol Endocrinol Metab 284: E671-678.

58. Klöckener T, Hess S, Belgardt BF, Paeger L, Verhagen LA, et al. (2011) Highfat feeding promotes obesity via insulin receptor/PI3K-dependent inhibition of SF-1 VMH neurons. Nat Neurosci 14: 911-918.

59. Rodríguez A, Catalán V, Gómez-Ambrosi J, García-Navarro S, Rotellar F, et al. (2011) Insulin- and leptin-mediated control of aquaglyceroporins in human adipocytes and hepatocytes is mediated via the PI3K/Akt/mTOR signaling cascade. J Clin Endocrinol Metab 96: E586-597.

60. Li Z, Shen J, Wu WK, Yu X, Liang J, et al. (2012) Leptin induces cyclin D1 expression and proliferation of human nucleus pulposus cells via JAK/STAT, PI3K/Akt and MEK/ERK pathways. PLoS One 7: e53176.

61. Jantarajit W, Thongon N, Pandaranandaka J, Teerapornpuntakit J, Krishnamra $\mathrm{N}$, et al. (2007) Prolactin-stimulated transepithelial calcium transport in duodenum and Caco-2 monolayer are mediated by the phosphoinositide 3-kinase pathway. Am J Physiol Endocrinol Metab 293: E372-384.

62. Vargas ML, Abella C, Hernandez J (2001) Diazepam increases the hypothalamic-pituitary-adrenocortical (HPA) axis activity by a cyclic AMPdependent mechanism. Br J Pharmacol 133: 1355-1361.

63. Kumari M, Cover PO, Poyser RH, Buckingham JC (1997) Stimulation of the hypothalamo-pituitary-adrenal axis in the rat by three selective type- 4 phosphodiesterase inhibitors: in vitro and in vivo studies. Br J Pharmacol 121 459-468.

64. Basta-Kaim A, Budziszewska B, Jaworska-Feil L, Tetich M, Kubera M, et al. (2006) Antipsychotic drugs inhibit the human corticotropin-releasing-hormone gene promoter activity in neuro-2A cells-an involvement of protein kinases. Neuropsychopharmacology 31: 853-865.

65. Allan BJ, Thorson CM, Van Haren RM, Parikh PP, Lew JI (2013) Risk of concomitant malignancy in hyperfunctioning adrenal incidentalomas. J Surg Res.

66. Midorikawa S, Sanada H, Hashimoto S, Suzuki T, Watanabe T (2001) The improvement of insulin resistance in patients with adrenal incidentaloma by surgical resection. Clin Endocrinol (Oxf) 54: 797-804.

67. Zoja C, Cattaneo S, Fiordaliso F, Lionetti V, Zambelli V, et al. (2011) Distinct cardiac and renal effects of ETA receptor antagonist and ACE inhibitor in experimental type 2 diabetes. Am J Physiol Renal Physiol 301: F1114-1123.

68. Bruhn-Olszewska B, Korzon-Burakowska A, Gabig-CimiÅ,ska M, Olszewski P WÄ ${ }^{\mathrm{TM}}$ grzyn A, et al. (2012) Molecular factors involved in the development of diabetic foot syndrome. Acta Biochim Pol 59: 507-513.

69. de Wit M, Wiaterek GK, Gray ND, Goulet KE, Best AM, et al. (2010) Relationship between alcohol use disorders, cortisol concentrations, and cytokine levels in patients with sepsis. Crit Care 14: R230.

70. Pitchot W, Herrera C, Ansseau M (2001) HPA axis dysfunction in majo depression: relationship to $5-\mathrm{HT}(1 \mathrm{~A})$ receptor activity. Neuropsychobiology 44 74-77.

71. Turns $M$ (2011) The diabetic foot: an overview of assessment and complications Br J Nurs 20: S19-25.

72. Blakytny R, Jude EB (2009) Altered molecular mechanisms of diabetic foot ulcers. Int J Low Extrem Wounds 8: 95-104.

73. Bitar MS, Al-Mulla F (2012) ROS constitute a convergence nexus in the development of IGF1 resistance and impaired wound healing in a rat model of type 2 diabetes. Dis Model Mech 5: 375-388. 
Citation: Torres RC, Prevatto JP, Silva PMR, Martinsand MA, Carvalho VF (2013) From Type-1 Diabetes HPA Axis to the Disease Complications. J Diabetes Metab S12: 002. doi:10.4172/2155-6156.S12-002

74. Bitar MS (1998) Glucocorticoid dynamics and impaired wound healing in diabetes mellitus. Am J Pathol 152: 547-554

75. Woo K (2012) Chronic Wound-associated Pain, Psychological Stress, and Wound Healing. Surg Technol Int XXII.

76. Ebrecht M, Hextall J, Kirtley LG, Taylor A, Dyson M, et al. (2004) Perceived stress and cortisol levels predict speed of wound healing in healthy male adults. Psychoneuroendocrinology 29: 798-809.

77. Broadbent E, Koschwanez HE (2012) The psychology of wound healing. Curr Opin Psychiatry 25: 135-140.

78. Detillion CE, Craft TK, Glasper ER, Prendergast BJ, DeVries AC (2004) Social facilitation of wound healing. Psychoneuroendocrinology 29: 1004-1011.

79. BjelakoviÄ $\ddagger$, StojanoviÄ $\mathrm{G}$, et al. (2010) Metabolic correlations of glucocorticoids and polyamines in inflammation and apoptosis. Amino Acids 39: 29-43.

80. Griselda CM (2011) D-arginine action against neurotoxicity induced by glucocorticoids in the brain. Neurosci Biobehav Rev 35: 1353-1362.

81. Walters EH, Reid D, Soltani A, Ward C (2008) Angiogenesis: a potentially critical part of remodelling in chronic airway diseases? Pharmacol Ther 118 : 128-137.

82. Oliver A, Ciulla TA (2006) Corticosteroids as antiangiogenic agents. Ophthalmo Clin North Am 19: 345-351, v.

83. Meerwaldt R, Odink RJ, Landaeta R, Aarts F, Brunekreef B, et al. (2002) A lower prevalence of atopy symptoms in children with type 1 diabetes mellitus. Clin Exp Allergy 32: 254-255

84. de F Carvalho V, Campos LV, Farias-Filho FA, Florim LT, Barreto EO, et al (2008) Suppression of allergic inflammatory response in the skin of alloxandiabetic rats: relationship with reduced local mast cell numbers. Int Arch Allergy Immunol 147: 246-254.

85. Diaz BL, Serra MF, Alves AC, Pires AL, Corrêa FM, et al. (1996) Alloxan diabetes reduces pleural mast cell numbers and the subsequent eosinophil influx induced by allergen in sensitized rats. Int Arch Allergy Immunol 111: $36-$ 43.

86. Carvalho VF, Barreto EO, Diaz BL, Serra MF, Azevedo V, et al. (2003) Systemic anaphylaxis is prevented in alloxan-diabetic rats by a mechanism dependent on glucocorticoids. Eur J Pharmacol 472: 221-227.

87. Koh GC, Peacock SJ, van der Poll T, Wiersinga WJ (2012) The impact of diabetes on the pathogenesis of sepsis. Eur J Clin Microbiol Infect Dis 31: 379 388.

88. Dooley KE, Chaisson RE (2009) Tuberculosis and diabetes mellitus: convergence of two epidemics. Lancet Infect Dis 9: 737-746.

89. Dixon WG, Abrahamowicz M, Beauchamp ME, Ray DW, Bernatsky S, et al (2012) Immediate and delayed impact of oral glucocorticoid therapy on risk of serious infection in older patients with rheumatoid arthritis: a nested casecontrol analysis. Ann Rheum Dis 71: 1128-1133.

90. Jick SS, Lieberman ES, Rahman MU, Choi HK (2006) Glucocorticoid use, other associated factors, and the risk of tuberculosis. Arthritis Rheum 55: 19-26.

91. Christ-Crain M, Opal SM (2010) Clinical review: the role of biomarkers in the diagnosis and management of community-acquired pneumonia. Crit Care 14: 203.

92. Grossman E, Messerli FH (2008) Hypertension and diabetes. Adv Cardiol 45 82-106.

93. Baid S, Nieman LK (2004) Glucocorticoid excess and hypertension. Curr Hypertens Rep 6: 493-499.

94. Sato A, Suzuki H, Nakazato Y, Shibata H, Inagami T, et al. (1994) Increased expression of vascular angiotensin II type $1 \mathrm{~A}$ receptor gene in glucocorticoidinduced hypertension. J Hypertens 12: 511-516.

95. Aras-Lopez R, Xavier FE, Ferrer M, Balfagon G (2009) Dexamethasone decreases neuronal nitric oxide release in mesenteric arteries from hypertensive rats through decreased protein kinase C activation. Clin Sci (Lond) 117: 305312.

96. Mangiapane H (2012) Cardiovascular disease and diabetes. Adv Exp Med Bio 771: $219-228$
97. Fantidis $P(2010)$ The role of the stress-related anti-inflammatory hormones ACTH and cortisol in atherosclerosis. Curr Vasc Pharmacol 8: 517-525.

98. García RA, Search DJ, Lupisella JA, Ostrowski J, Guan B, et al. (2013) $11 \hat{\imath}^{2}$-hydroxysteroid dehydrogenase type 1 gene knockout attenuates atherosclerosis and in vivo foam cell formation in hyperlipidemic apoEâ »/â " mice. PLoS One 8: e53192.

99. Hadoke PW, Iqbal J, Walker BR (2009) Therapeutic manipulation of glucocorticoid metabolism in cardiovascular disease. $\mathrm{Br} \mathrm{J}$ Pharmacol 156: 689 712.

100. Banerjee C, Moon YP, Paik MC, Rundek T, Mora-McLaughlin C, et al. (2012) Duration of diabetes and risk of ischemic stroke: the Northern Manhattan Study. Stroke 43: 1212-1217.

101. Cheng G, Huang C, Deng H, Wang H (2012) Diabetes as a risk factor for dementia and mild cognitive impairment: a meta-analysis of longitudinal studies. Intern Med J 42: 484-491.

102. Sugimoto K, Yasujima M, Yagihashi S (2008) Role of advanced glycation end products in diabetic neuropathy. Curr Pharm Des 14: 953-961.

103. Wada R, Yagihashi S (2005) Role of advanced glycation end products and their receptors in development of diabetic neuropathy. Ann N Y Acad Sci 1043 : 598-604.

104. Sima AA, Zhang W, Grunberger G (2004) Type 1 diabetic neuropathy and C-peptide. Exp Diabesity Res 5: 65-77.

105. Vincent AM, Callaghan BC, Smith AL, Feldman EL (2011) Diabetic neuropathy: cellular mechanisms as therapeutic targets. Nat Rev Neurol 7: 573-583.

106. Stranahan AM, Arumugam TV, Cutler RG, Lee K, Egan JM, et al. (2008) Diabetes impairs hippocampal function through glucocorticoid-mediated effects on new and mature neurons. Nat Neurosci 11: 309-317.

107. Brureau A, Zussy C, Delair B, Ogier C, Ixart G, et al. (2013) Deregulation of hypothalamic-pituitary-adrenal axis functions in an Alzheimer's disease rat model. Neurobiol Aging 34: 1426-1439.

108. Valassi E, Crespo I, Santos A, Webb SM (2012) Clinical consequences of Cushing's syndrome. Pituitary 15: 319-329.

109.Pedersen WA, McMillan PJ, Kulstad JJ, Leverenz JB, Craft S, et al. (2006) Rosiglitazone attenuates learning and memory deficits in Tg2576 Alzheime mice. Exp Neurol 199: 265-273.

110. Torres RC, Batista MM, Pons AH, Silva AR, Cordeiro RS, et al. (2012) Activation of PPAR ${ }^{3}$ by restores mast cell numbers and reactivity in alloxandiabetic rats by reducing the systemic glucocorticoid levels. Eur J Pharmaco 691: 261-267.

111. Gragnoli C (2012) Depression and type 2 diabetes: cortisol pathway implication and investigational needs. J Cell Physiol 227: 2318-2322.

112. Nouwen A, Winkley K, Twisk J, Lloyd CE, Peyrot M, et al. (2010) Type 2 diabetes mellitus as a risk factor for the onset of depression: a systematic review and meta-analysis. Diabetologia 53: 2480-2486.

113. Müller MB, Zimmermann S, Sillaber I, Hagemeyer TP, Deussing JM, et al. (2003) Limbic corticotropin-releasing hormone receptor 1 mediates anxietyrelated behavior and hormonal adaptation to stress. Nat Neurosci 6: 11001107.

114. Chrousos GP, Gold PW (1998) A healthy body in a healthy mind--and vice versa--the damaging power of "uncontrollable" stress. J Clin Endocrinol Metab 83: $1842-1845$.

115. Bitar MS, Farook T, Wahid S, Francis IM (1999) Glucocorticoid-dependent impairment of wound healing in experimental diabetes: amelioration by adrenalectomy and RU 486. J Surg Res 82: 234-243.

116. Diaz B, Barreto E, Cordeiro R, Perretti M, Martins M, et al. (2001) Enhanced serum glucocorticoid levels mediate the reduction of serosal mast cell numbers in diabetic rats. Life Sci 68: 2925-2932.

117. Bechtold AG, Patel G, Hochhaus G, Scheuer DA (2009) Chronic blockade of hindbrain glucocorticoid receptors reduces blood pressure responses to novel stress and attenuates adaptation to repeated stress. Am J Physiol Regul Integr Comp Physiol 296: R1445-1454

118. Revsin Y, Rekers NV, Louwe MC, Saravia FE, De Nicola AF, et al. (2009) Glucocorticoid receptor blockade normalizes hippocampal alterations 
Citation: Torres RC, Prevatto JP, Silva PMR, Martinsand MA, Carvalho VF (2013) From Type-1 Diabetes HPA Axis to the Disease Complications. J Diabetes Metab S12: 002. doi:10.4172/2155-6156.S12-002

Page 8 of 8

and cognitive impairment in streptozotocin-induced type 1 diabetes mice. Neuropsychopharmacology 34: 747-758.

119. Haynes LE, Griffiths MR, Hyde RE, Barber DJ, Mitchell IJ (2001) Dexamethasone induces limited apoptosis and extensive sublethal damage to specific subregions of the striatum and hippocampus: implications for mood disorders. Neuroscience 104: 57-69.

120. Balkaya M, Prinz V, Custodis F, Gertz K, Kronenberg G, et al. (2011) Stress worsens endothelial function and ischemic stroke via glucocorticoids. Stroke 42: 3258-3264. 